\title{
A Digitally Competent Health Workforce: Scoping Review of Educational Frameworks
}

Nuraini Nazeha ${ }^{1}$, BA; Deepali Pavagadhi ${ }^{1}$, MSc; Bhone Myint Kyaw ${ }^{1}$, MBBS, MSc, PhD; Josip Car ${ }^{1,2}$, MD, PhD, FRCPE, FFPH; Geronimo Jimenez ${ }^{1,3}$, MA; Lorainne Tudor $\mathrm{Car}^{2,4}$, MD, MSc, PhD

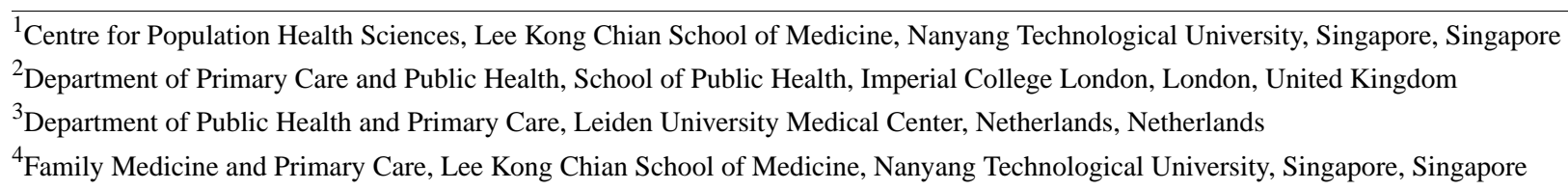

Corresponding Author:

Josip Car, MD, PhD, FRCPE, FFPH

Centre for Population Health Sciences

Lee Kong Chian School of Medicine

Nanyang Technological University

11 Mandalay Road

Singapore

Singapore

Phone: 6569047005

Email: josip.car@ntu.edu.sg

\section{Abstract}

Background: Digital health technologies can be key to improving health outcomes, provided health care workers are adequately trained to use these technologies. There have been efforts to identify digital competencies for different health care worker groups; however, an overview of these efforts has yet to be consolidated and analyzed.

Objective: The review aims to identify and study existing digital health competency frameworks for health care workers and provide recommendations for future digital health training initiatives and framework development.

Methods: A literature search was performed to collate digital health competency frameworks published from 2000. A total of 6 databases including gray literature sources such as OpenGrey, ResearchGate, Google Scholar, Google, and websites of relevant associations were searched in November 2019. Screening and data extraction were performed in parallel by the reviewers. The included evidence is narratively described in terms of characteristics, evolution, and structural composition of frameworks. A thematic analysis was also performed to identify common themes across the included frameworks.

Results: In total, 30 frameworks were included in this review, a majority of which aimed at nurses, originated from high-income countries, were published since 2016, and were developed via literature reviews, followed by expert consultations. The thematic analysis uncovered 28 digital health competency domains across the included frameworks. The most prevalent domains pertained to basic information technology literacy, health information management, digital communication, ethical, legal, or regulatory requirements, and data privacy and security. The Health Information Technology Competencies framework was found to be the most comprehensive framework, as it presented 21 out of the 28 identified domains, had the highest number of competencies, and targeted a wide variety of health care workers.

Conclusions: Digital health training initiatives should focus on competencies relevant to a particular health care worker group, role, level of seniority, and setting. The findings from this review can inform and guide digital health training initiatives. The most prevalent competency domains identified represent essential interprofessional competencies to be incorporated into health care workers' training. Digital health frameworks should be regularly updated with novel digital health technologies, be applicable to low- and middle-income countries, and include overlooked health care worker groups such as allied health professionals.

(J Med Internet Res 2020;22(11):e22706) doi: 10.2196/22706

\section{KEYWORDS}

digital health; eHealth; health professions education; digital competency; competency; framework; review; medical education 


\section{Introduction}

\section{Background}

Over the last three decades, there has been considerable interest in the use of digital health to enhance the quality, efficiency, and safety of health care [1,2]. Digital health and eHealth are often used interchangeably and broadly defined as "the use of information and communications technology in support of health and health-related fields" [3]. An analysis of various digital health definitions revealed three distinct yet overlapping uses such as monitoring, tracking, and informing health (eg, mobile devices, mobile sensors and wearables, apps, social media); enabling health communication among various stakeholders (eg, telehealth, virtual consultations); and storing, managing, and utilizing health data (eg, electronic medical records, electronic medication systems) [4]. Digital health tools have the potential to provide health care workers with a holistic view of patients' medical conditions through access to their health-related data and improved communication, regardless of distance and access [5]. Furthermore, the use of digital technology in health care could potentially reduce turnaround times, resource use, medication errors, and adverse drug events; increase the use of preventive care; and enable greater adherence to clinical guidelines [6-8].

Training and educating health care workers to be digitally competent is important for several reasons.

First, with the growing use of digital technology in health care, the roles and responsibilities of the health workforce are transforming in an unprecedented manner, intensifying the need for capacity building and continuous professional development. For example, a recent review commissioned by the United Kingdom Secretary of State for Health and Social Care (ie, the Topol Review) reported that within the next two decades, the majority of jobs in the National Health Service (NHS) will have a digital component [9]. Second, the importance and potential of remote care has been brought to light recently with the COVID-19 pandemic. Virtual consultation devices and electronic systems are indispensable tools used to diagnose and treat patients with potential COVID-19 infections as well as all other infections $[10,11]$. Third, even though the current and next generation of practitioners may be seen as "digital natives" [12], surveys of health care workers show that they would appreciate more training on digital technology [13,14]. Finally, improving digital literacy capabilities could lead to better adoption and implementation of digital services and technologies in health care settings [15]. Similarly, poor digital health literacy was found to be the most common barrier to the digital transformation of health care [16], and thus, the adoption of health technologies has been gradual in countries such as the United States [17], Europe [16], and Australia [18]. For the above-mentioned reasons, there is an increasing number of medical schools introducing digital health training into their curricula [12,19,20].

Such training programs should be guided by a clear framework of digital health competencies suited for different health care worker groups, settings, contexts, seniority, and role. Although there is an increasing number of individual digital health competency frameworks and reviews focusing on a specific health care worker role or setting [21-24], there is a need for consolidation, analysis, and a comprehensive overview of existing frameworks for all health care worker groups. This includes frameworks that are specific for and those that are relevant across different health professions, roles, or settings. Such an overview is important to inform increasingly interdisciplinary teams working in medicine and health care and corresponding future training initiatives, policy development, and research.

\section{Objectives}

The objective of this review is to identify and analyze the available digital health competency frameworks, regardless of health profession, role, or setting. This scoping review takes into consideration the heterogeneity and complexity of this field, and we aim to identify (1) the intended applications of digital health competency frameworks; (2) the methodologies employed; (3) the targeted audience in terms of health professions and settings; and (4) the type of competencies included in the frameworks. By doing so, we aim to provide an in-depth analysis of the existing frameworks as well as identify potential gaps and propose recommendations for the development of future frameworks and digital health training initiatives.

\section{Methods}

\section{Study Design}

We followed the guidelines by the Joanna Briggs Institute [25] in performing a literature review and guidelines by Tricco et al [26] in creating a Preferred Reporting Items for Systematic Reviews and Meta-Analyses (PRISMA) flow chart. The protocol for this review was registered with the Open Science Framework [27]. In this review, we used the World Health Organization's definition of digital health as "the combination of e-health and m-health as well as emerging areas, such as the use of advanced computing sciences in big data, genomics and artificial intelligence" [3].

\section{Eligibility Criteria}

We included studies and reports focusing on the development and reporting of a digital health competency framework for health care workers. In this review, a competency framework is defined as a repository or a model that identifies, enlists, structures, and organizes competencies into meaningful categories and that has been developed via a systematic methodology or a relevant, established organization. This definition was developed a priori by referring to the existing definitions and descriptions, and looking at the common features of formerly identified digital health competency frameworks applicable to health care workers [28]. We included studies and reports on all health professions, including pre- and in-service, health care settings, and languages. Studies before January 2000 were excluded because digital health has evolved at a rapid pace, with substantial changes over the last two decades. The details of the inclusion and exclusion criteria are listed in Multimedia Appendix 1. 


\section{Search Strategy}

The search strategy was developed collaboratively and iteratively by the reviewers with support from an experienced medical librarian and was guided by the following: (1) the sensitivity of the search strategy to relevant articles identified from previous manual searches and (2) the total number of relevant results in the first few pages of results in Medical Literature Analysis and Retrieval System Online (MEDLINE) and EMBASE (Excerpta Medica dataBASE). The final MEDLINE search strategy (Multimedia Appendix 2) was translated to other databases. Subsequently, the following 6 databases were searched on November 8, 2019: MEDLINE, EMBASE, Cumulative Index to Nursing and Allied Health Literature (CINAHL), Education Resources Information Center (ERIC), PsycINFO, and the Cochrane Library. MEDLINE, EMBASE, ERIC, and PsycINFO were accessed via the Ovid platform, and CINAHL was accessed via EBSCOhost. We expected that there would be substantial unpublished work in this area, for which searches were performed using pertinent keywords (Multimedia Appendix 3) in OpenGrey, ResearchGate, and the first 10 pages of Google and Google Scholar. Websites of relevant professional associations (eg, International Medical Informatics Association [IMIA]), accreditation councils (eg, the US Accreditation Council for Graduate Medical Education [ACGME]), and key government websites (eg, Digital Health Canada, NHS Digital) were also searched (Multimedia Appendix 4).

\section{Screening and Data Extraction}

The reviewers screened the search results and assessed the full-text studies for inclusion. For the title and abstract screening, Covidence tool [29], a web-based software platform, and, for full-text screening, EndNote X8 were used. Subsequently, a data extraction form was used to record information from the selected full-text studies using Microsoft Excel. The form was developed to be in line with the research objectives and was piloted by reviewers on 3 studies. The form was further amended (Multimedia Appendix 5), and relevant data were extracted by reviewers. Each round of screening and data extraction process was performed by a pair of reviewers independently, and results were compared thereafter. Disagreements between reviewers were resolved by discussion, and where required, a third reviewer was engaged as an arbiter.

\section{Data Synthesis}

We analyzed the identified digital health competency frameworks in terms of their coverage of health professions, education level (eg, preservice or in-service), geographical applicability (ie, local or organizational, regional, national, international), health care settings (eg, acute care, emergency care, primary care), and other comparable features such as source and methodology. In frameworks that did not specify their methodology, an additional internet search was performed to retrieve information on the methods employed for framework development. Following this, we narratively synthesized and described framework characteristics, the evolution of frameworks over time, and the structural composition of competencies.

In addition, we performed a thematic analysis according to a list of steps proposed by Nowell et al [30] to understand the types of digital health competency categories presented in the frameworks. From the included frameworks, 2 reviewers independently classified competency categories into overarching domains. Studies that did not publish the full version of the framework were excluded from the thematic analysis, together with competency categories that were aimed at non-health care workers in a health care setting or irrelevant to digital competencies. Frameworks with ambiguous categories were excluded unless pertaining category descriptions or competencies were provided. Frameworks with competency themes or statements, with no distinct categories, were also included in the analysis by carefully allocating them to the identified domains. In some cases, where a single competency statement or theme encompassed several components of a competency, it was allocated to more than one relevant domain. After discussion and consensus, the reviewers derived a consolidated list of identified domains and their definitions and the prevalence of each identified domain across the included frameworks.

\section{Results}

\section{Study Characteristics}

The search generated 14,229 articles, of which 14,091 were from database searches and 138 from gray literature. After duplicates were removed and screening was completed, 33 articles were deemed eligible for inclusion. Of these, 27 articles presented individual frameworks. The remaining 6 articles presented preliminary findings followed by finalized versions of their frameworks (Staggers et al [31,32]; Egbert et al [33,34]; Hubner et al $[35,36]$ ), adding 3 more individual frameworks. As a result, a total of 30 frameworks are presented in this review (Figure 1), of which 16 were found through a gray literature search. 
Figure 1. PRISMA (Preferred Reporting Items for Systematic Reviews and Meta-Analyses) flow chart.

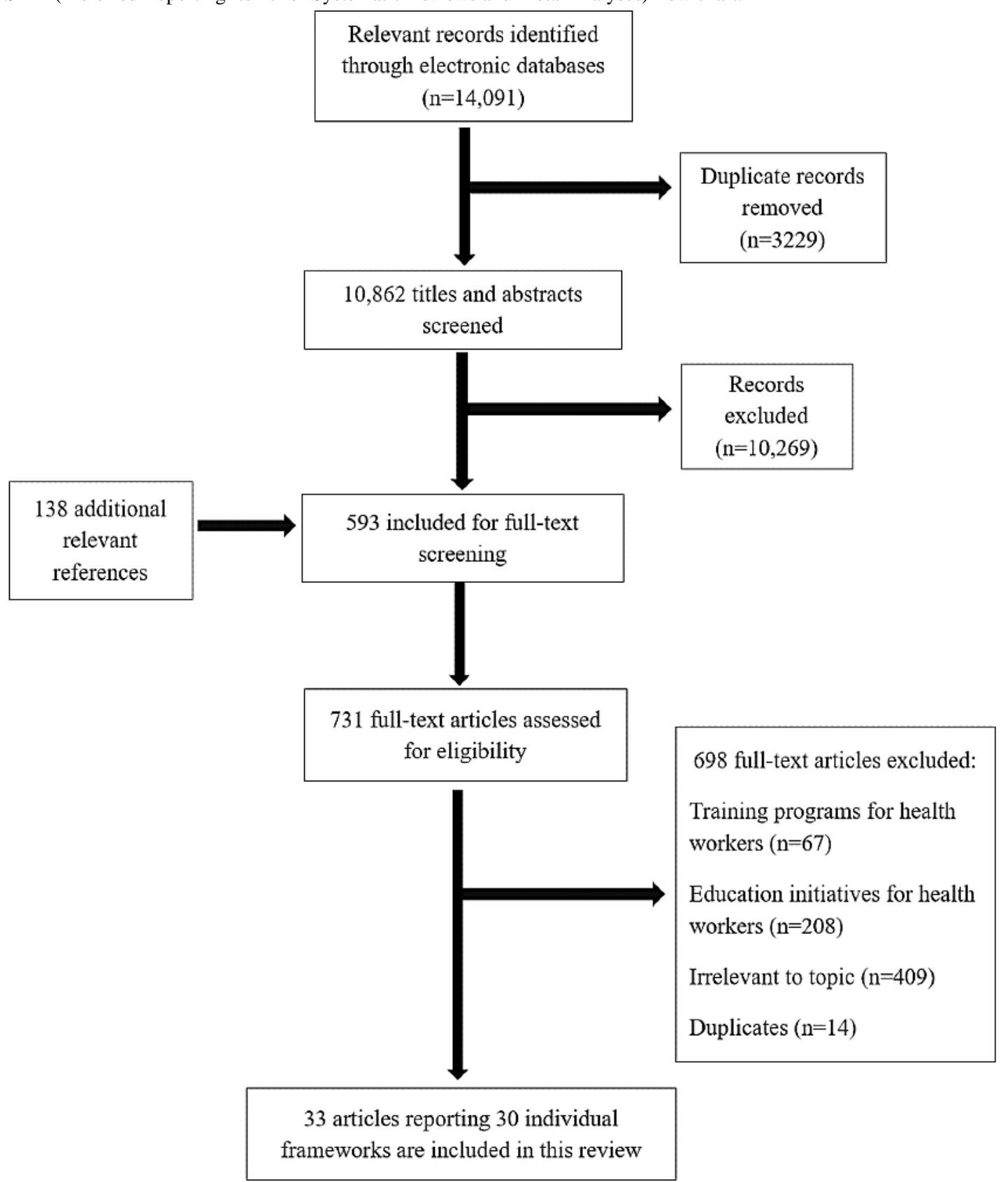

In terms of methodology, 14 frameworks employed literature review as an initial step, subsequently finalizing the frameworks through the use of expert consultations $(n=5)$ [37-41], focus group discussions $(n=3)[33,34,42,43]$, Delphi methodology $(n=5)$ [31,32,44-47], or expert surveys [48]. In total, 11 other frameworks used one or a combination of methodologies (ie, Delphi, expert discussions, workshops, surveys) to reach consensus, largely by engaging various experts such as informaticists, health professionals, educators, and academics $[21,22,36,49-56]$. Of the remaining frameworks, 2 used only literature review to select relevant competencies [57,58], and 3 frameworks were built on the foundation of other published frameworks [59-61]. In addition, the frameworks were developed by a team of authors from a single university or institute (eg, University of Minnesota, School of Nursing) [44], by an international- or national-level organization (eg, IMIA, Australian Health Informatics Council [AHIEC]) [49,57], or by means of a collaborative effort to produce frameworks such as Technology Informatics Guiding Education Reform (TIGER) $[35,36,52]$ and Health Information Technology Competencies (HITCOMP) [41].

In terms of geographical relevance, 15 frameworks were country-specific $[21,33,37,38,40,42,45,47,48,50,55-59], 1$ was specific to the European Union region [61], 5 were applicable globally $[35,36,41,49,52,54]$, and the remaining did not specify $(n=9)$. In terms of health care settings, 4 were developed for remote care delivery $[39,51,53,60], 1$ framework each for hospitals [48], acute care [41], and homecare [50], while the remaining frameworks either were applicable to all health care settings $(n=5)[42,45,56,57,59]$ or did not specify $(n=18)$. In terms of health professions, 14 frameworks targeted nurses, 4 targeted doctors, of which one also included dentists, and 1 framework each targeted psychiatrists, dietitians, and public health professionals; 9 frameworks targeted health care workers 
in general, of which 5 specified the inclusion of administrative, information technology (IT) support, and health informatics specialist roles [41,52,54,57,61], and 1 specified the inclusion of allied health professionals [39]. Among the nursing frameworks, 7 were meant for in-service nurses [21,31,32,42-44,46,48], 5 for preservice nursing students [33-37,53,58], and 2 for both [22,50]. Of the 4 medicine-focused frameworks, one focused on in-service doctors [40], another on preservice medical students [55], and 2 on both [59,60]. The framework characteristics and summary of the findings of the included studies are presented in Table 1 and Table 2, respectively. Additional details of the included studies are presented in Multimedia Appendix 6 [21,22,31-63].

Table 1. Characteristics of the 30 frameworks.

\begin{tabular}{|c|c|}
\hline Characteristics & Values, n (\%) \\
\hline \multicolumn{2}{|l|}{ Publication dates } \\
\hline $2000-2010$ & $6(20)$ \\
\hline 2010-2019 & $24(80)$ \\
\hline \multicolumn{2}{|l|}{ Source } \\
\hline Database & $14(47)$ \\
\hline Gray literature & $16(53)$ \\
\hline \multicolumn{2}{|l|}{ Geographical setting } \\
\hline Country & $15(50)$ \\
\hline Region & $1(3)$ \\
\hline International & $5(17)$ \\
\hline Not specified & $9(30)$ \\
\hline \multicolumn{2}{|l|}{ Health care setting } \\
\hline Acute care & $1(3)$ \\
\hline Home care & $1(3)$ \\
\hline Hospitals & $1(3)$ \\
\hline Remote care & $4(13)$ \\
\hline All health care settings & $5(17)$ \\
\hline Not specified & $18(60)$ \\
\hline \multicolumn{2}{|l|}{ Health care profession } \\
\hline Nursing & $14(47)$ \\
\hline Medicine & $4(13)$ \\
\hline Allied health & $1(3)$ \\
\hline Psychiatry & $1(3)$ \\
\hline Public health professionals & $1(3)$ \\
\hline Unspecified or applicable to multiple health professions & $9(30)$ \\
\hline \multicolumn{2}{|l|}{ Educational level } \\
\hline In-service & $13(43)$ \\
\hline Preservice & $9(30)$ \\
\hline Both & $8(27)$ \\
\hline
\end{tabular}


Table 2. Summary of findings of included studies.

\begin{tabular}{|c|c|c|c|c|}
\hline Study ID & $\begin{array}{l}\text { Context (country; health } \\
\text { care setting) }\end{array}$ & $\begin{array}{l}\text { Intended audience (profes- } \\
\text { sion; educational level) }\end{array}$ & Methodology & Organization of framework \\
\hline $\begin{array}{l}\text { Academy of Medical } \\
\text { Royal Colleges (2011) } \\
{[59]}\end{array}$ & Scotland; all & $\begin{array}{l}\text { Doctors and dentists; preser- } \\
\text { vice and in-service }\end{array}$ & $\begin{array}{l}\text { Framework aligned with other } \\
\text { competency frameworks }\end{array}$ & $\begin{array}{l}418 \text { competencies divided into } \\
20 \text { domains, and further subdi- } \\
\text { vided into outcomes (ie, } \\
\text { knowledge, skills, behavior) }\end{array}$ \\
\hline AHIEC $^{\mathrm{a}}(2011)$ [57] & Australia; all & $\begin{array}{l}\text { All HCPs }{ }^{b} \text { including admin } \\
\text { and } \mathrm{IT}^{\mathrm{c}} \text { support staff; preser- } \\
\text { vice and in- service }\end{array}$ & $\begin{array}{l}\text { Literature review drew on a } \\
\text { wide range of major initiatives }\end{array}$ & $\begin{array}{l}45 \text { competencies grouped into } \\
3 \text { categories and assigned a } \\
\text { competency level ranging from } \\
1 \text { to } 6\end{array}$ \\
\hline $\begin{array}{l}\text { AFMC }^{d} \text { in Partnership } \\
\text { with Canada Health In- } \\
\text { foway (2014) [55] }\end{array}$ & Canada; not specified & Medical students; preservice & $\begin{array}{l}\text { Framework was based on con- } \\
\text { tributions from experts }\end{array}$ & $\begin{array}{l}25 \text { competencies classified ac- } \\
\text { cording to physicians' roles and } \\
\text { each competency is further di- } \\
\text { vided into preclinical and } \\
\text { clerkship milestones }\end{array}$ \\
\hline
\end{tabular}

Australian Nursing and Australia; all Midwifery Federation (2015) [42]

Ayres (2012) [45]

Barakat (2013) [50]

Brunner (2018) [47]

Chang (2011) [21]

Collins (2017) [46]

Crawford (2016) [51]

Curran (2003) [22]

Egbert (2016) [33]; Egbert (2019) [34]

HITCOMP $^{\mathrm{e}}$ (2019) [41] International; acute care

Hilty (2015) [60]
Not specified

The Netherlands; home care

Australia; not specified

Taiwan; not specified

Nurses; in-service

Nurse leaders; in-service

Not specified; remote care

Not specified

Austria, Switzerland, Germany; not specified service service vice

Nurses; preservice preservice and in-service
Nurses and midwives (registered nurses, midwives, and enrolled nurses); in-service

Registered dietitians, and dietetic technicians, registered and students; preservice and in-service

Nurses; pre-service and in-

Health graduates; preservice

shop with academic experts

- Literature review

- Focus group discussion

- Delphi study

3 web-based Delphi rounds conducted with experts

- Literature review

- Delphi study (3 rounds)

- Exploratory factor analysis for scale optimization and factor identification

Psychiatry residents; in-ser- Expert panel and interviews

Nurse practitioners; preservice and in-service with faculty and psychiatry residences

Consensus with a team of nurse informaticists and nurse practitioner program directors

- Literature review

- Expert survey

- Focus group discussion and consensus

- $\quad$ Literature review

- Survey sent to international experts

- Gap analysis

- Expert consultation

Doctors, medical students;
Competencies organized using Competencies listed for 8 main the US ACGME framework, categories and subcategories, with input from the CanMEDS for each level of practice framework
15 competencies sorted by professional roles, with examples

32 competencies grouped into 3 categories

24 competency areas identified, and 5 of the most relevant areas ranked for 5 nursing roles

1025 competencies organized into 33 competency areas, for 5 levels of practice across 5 domains 


\begin{tabular}{|c|c|c|c|c|}
\hline Study ID & $\begin{array}{l}\text { Context (country; health } \\
\text { care setting) }\end{array}$ & $\begin{array}{l}\text { Intended audience (profes- } \\
\text { sion; educational level) }\end{array}$ & Methodology & Organization of framework \\
\hline Honey (2018) [58] & $\begin{array}{l}\text { New Zealand; not speci- } \\
\text { fied }\end{array}$ & $\begin{array}{l}\text { Registered nurses; preser- } \\
\text { vice }\end{array}$ & $\begin{array}{ll}\text { - } & \text { Curriculum mapping } \\
\text { - } & \text { Literature review }\end{array}$ & $\begin{array}{l}4 \text { domains identified, and rele- } \\
\text { vant subcategories and exam- } \\
\text { ples presented for each domain }\end{array}$ \\
\hline Hubner (2016) [35] & $\begin{array}{l}\text { International; not speci- } \\
\text { fied }\end{array}$ & Nurses; preservice & $\begin{array}{l}\text { - Survey sent to internation- } \\
\text { al experts } \\
\text { A workshop was held to } \\
\text { validate competencies }\end{array}$ & $\begin{array}{l}24 \text { competency areas identified, } \\
\text { and } 6 \text { of the most relevant areas } \\
\text { ranked for } 5 \text { nursing roles }\end{array}$ \\
\hline Hubner (2018) [36] & $\begin{array}{l}\text { International; not speci- } \\
\text { fied }\end{array}$ & Nurses; preservice & $\begin{array}{l}\text { - Survey sent to internation- } \\
\text { al experts } \\
\text { - } \quad \text { A workshop was held to } \\
\text { validate competencies }\end{array}$ & $\begin{array}{l}\text { - } 24 \text { competency areas } \\
\text { identified, and sorted into } \\
6 \text { overarching domains } \\
10 \text { of the most relevant ar- } \\
\text { eas ranked for } 5 \text { nursing } \\
\text { roles }\end{array}$ \\
\hline
\end{tabular}

Hubner (2019) [52] International; not speci- All HCPs; preservice fied

Hwang (2008) [48]

Jidkov (2019) [40]

Maheu (2018) [39]

Mantas (2010) [49]

Nagle (2014) [37]

NHS (2018) [56]
International; not speci- All HCPs; in-service fied

Canada; not specified

United Kingdom; all
Registered nurses; preservice

All HCPs; in-service
- $\quad$ Adapted Hubner (2016 and 2018)'s work [35,36] to include more HCP roles

- Survey was sent to international experts

Clinical nurses; in-service

- Literature review

- Expert survey

- Literature review

- Curricular content analysis

- Expert consultation

All HCPs including allied health professionals; Preservice and in-service

- Literature review

- Expert consultation

Recommendations were discussed and refined by the IMIA $^{\mathrm{f}}$ task force.

- Literature review

- Consensus with experts through 3 rounds of feedback

Consultations with different stakeholders and workforce groups [62]
33 competency areas are identified, and the 10 most relevant competencies are ranked for each HCP role

49 competencies grouped into 3 main categories and subcategories

20 competencies organized into 6 domains

7 domains identified, which are further broken down into 51 telebehavioral objectives, followed by 149 telebehavioral practices across 3 levels

34 competencies organized into $3 \mathrm{BMHI}^{\mathrm{g}}$ domains and each competency is determined if it is required by an IT user or a BMHI specialist according to 3 proficiency levels

19 competencies grouped into 3 domains.

An overarching domain broken down into 5 domains, each with a set of description and competencies sorted according to 4 proficiency levels 


\begin{tabular}{|c|c|c|c|}
\hline Study ID & $\begin{array}{l}\text { Context (country; health } \\
\text { care setting) }\end{array}$ & $\begin{array}{l}\text { Intended audience (profes- } \\
\text { sion; educational level) }\end{array}$ & Methodology \\
\hline $\begin{array}{l}\text { Public Health Informatics } \\
\text { Institute (2016) [38] }\end{array}$ & $\begin{array}{l}\text { United States; not speci- } \\
\text { fied }\end{array}$ & $\begin{array}{l}\text { Public health professionals; } \\
\text { in-service }\end{array}$ & $\begin{array}{ll}\text { - } & \text { Literature review } \\
\text { - } & \text { Expert consultation }\end{array}$ \\
\hline JASEHN (2018) [61] & Region; not specified & $\begin{array}{l}\text { All HCPs including admin } \\
\text { and IT support staff; in-ser- } \\
\text { vice }\end{array}$ & $\begin{array}{l}\text { - } \quad \text { Literature review } \\
\text { Framework aligned with } \\
\text { roles and competences as } \\
\text { per the European eCompe- } \\
\text { tence Framework } \\
\text { Use of framework descrip- } \\
\text { tions to determine skill } \\
\text { level for each role [63] }\end{array}$ \\
\hline
\end{tabular}

Organization of framework

8 categories identified, each with a set of competency statement and competencies

- Model 1: mission and main tasks described for 3 main profiles of health care workers (ie, health, nonhealth, and IT)

- Model 2: 52 competencies grouped into 6 domains, where each competency has a description, and a set of associated knowledge and skill, according to 5 proficiency levels

\begin{tabular}{|c|c|c|c|c|}
\hline Staggers (2001) [31] & Not specified & Nurses; in-service & $\begin{array}{ll}\text { - } & \text { Literature review } \\
\text { - } & \text { Consensus with experts }\end{array}$ & $\begin{array}{l}304 \text { competencies grouped into } \\
3 \text { categories for each level of } \\
\text { practice }\end{array}$ \\
\hline Staggers (2002) [32] & Not specified & Nurses; in-service & $\begin{array}{l}\text { Follow-up from Staggers } \\
\text { (2001) [31] } \\
\text { - } 3 \text { Delphi rounds were } \\
\text { conducted }\end{array}$ & $\begin{array}{l}281 \text { competencies grouped into } \\
3 \text { categories for each level of } \\
\text { practice }\end{array}$ \\
\hline Thye (2018) [54] & $\begin{array}{l}\text { International; not speci- } \\
\text { fied }\end{array}$ & $\begin{array}{l}\text { All HCPs including admin } \\
\text { and IT support staff; preser- } \\
\text { vice }\end{array}$ & 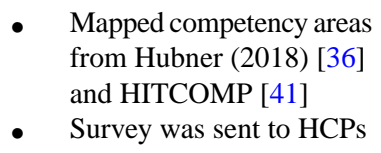 & $\begin{array}{l}33 \text { competency areas identified, } \\
\text { and the } 10 \text { most relevant inter- } \\
\text { professional areas are listed }\end{array}$ \\
\hline Trangenstein (2009) [43] & Not specified & Nurse scholars; in-service & $\begin{array}{ll}\text { - } & \text { Literature review } \\
\text { - } & \text { Discussion and consensus }\end{array}$ & $\begin{array}{l}7 \text { competency domains sorted } \\
\text { according to nursing level of } \\
\text { practice }\end{array}$ \\
\hline $\begin{array}{l}\text { Van Houwelingen (2016) } \\
\text { [53] }\end{array}$ & $\begin{array}{l}\text { Not specified; remote } \\
\text { care }\end{array}$ & Nurses; preservice & $\begin{array}{l}\text { - Survey with competencies } \\
\text { was sent to participants } \\
\text { - } \quad \text { Delphi study (4 rounds) }\end{array}$ & $\begin{array}{l}52 \text { competencies organized into } \\
3 \text { categories, where skills are } \\
\text { further subdivided into } 5 \text { do- } \\
\text { mains }\end{array}$ \\
\hline $\begin{array}{l}\text { Westra and Delaney } \\
(2008)[44]\end{array}$ & Not specified & Nurse leaders; in-service & $\begin{array}{ll}\text { - } & \text { Literature review } \\
\text { - } & \text { Delphi study }\end{array}$ & $\begin{array}{l}92 \text { competency areas are } \\
\text { grouped into } 3 \text { categories }\end{array}$ \\
\hline
\end{tabular}

${ }^{a}$ AHIEC: Australian Health Informatics Education Council.

${ }^{\mathrm{b}} \mathrm{HCP}$ : health care professional.

${ }^{\mathrm{c}}$ IT: information technology.

dAFMC: Association of Faculties of Medicine of Canada.

${ }^{\mathrm{e}}$ HITCOMP: Health Information Technology Competencies.

f IMIA: International Medical Informatics Association.

${ }^{\mathrm{B}}$ BMI: biomedical and health informatics.

\section{Evolution of Frameworks}

The digital health competency frameworks have drawn upon each other and have incrementally advanced the recommendations made in this area, as presented in Figures 2 and 3. The initial work of Staggers et al [31,32], which targeted nurses at 4 levels of practice, has been reproduced and adapted to suit different nursing roles (eg, nurse leaders, nurse practitioners) [22,44], health professions (eg, dietitians) [45], and even geographical settings (eg, Taiwan, Canada; Figure 2) $[37,48]$. In another instance, to propose competencies for nurse leaders, Collins et al [46] expanded and reorganized competency categories from Westra and Delaney [44], which initially drew inspiration from the framework by Staggers et al [31,32]. The framework by Staggers et al [31,32] was updated 10 years later by Chang et al [21] with 42 new competencies.

Another commonly referenced framework is that by Egbert et al (Figure 3) [33,34]. This framework identified 24 core competency areas and conducted a survey with experts to rank the most relevant competency areas for nurses in Austria, Switzerland, and Germany. The same survey with 24 core competency areas was then sent to multiple countries to put forth international recommendations for nursing informatics, widely known as the TIGER framework $[35,36]$. The TIGER framework grouped the core competency areas into 6 
overarching domains (ie, data, information and knowledge, information exchange and information sharing, ethics and legal issues, systems life cycle management, management in informatics, biostatistics, and medical technology) and ranked the most relevant competencies for nursing internationally.
Subsequently, the TIGER framework prompted its 2.0 version to include a wider spectrum of health care workers [52], and inspired the work by Thye et al [54] where interprofessional competencies were identified.

Figure 2. Digital health competency frameworks adapted from Staggers framework.

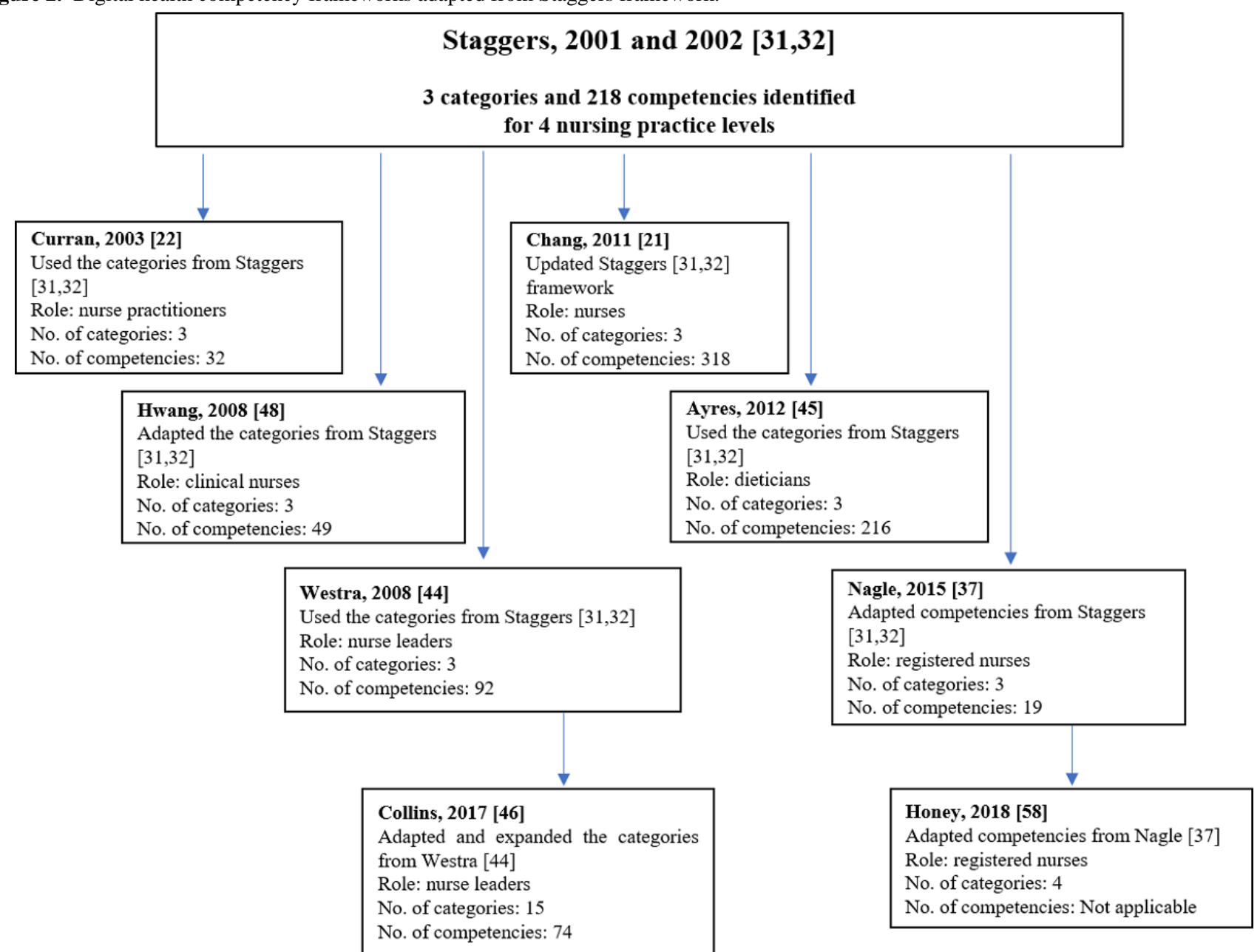

One framework that was accessible through an open-source internet-based database is the HITCOMP Tool and Repository [41]. HITCOMP was produced by the eHealth Workforce Development Workgroup as part of the EU*US eHealth Work Project. Its overall goal was to map, quantify, and project the needs of a digitally competent workforce [64]. This tool covers the digital competencies required in acute care settings for 5 broad roles of health care workers, similar to the TIGER framework version 2.0 (ie, direct patient care; administration; engineering or information, communication, and technology; informatics; and research or biomedicine) [52]. In comparison with the other included frameworks, the HITCOMP framework has the highest number of competencies at 1025 .

Other frameworks that inspired the development of subsequent frameworks include the IMIA [49], which was adapted by the AHIEC [57] to create national informatics standards for Australian health professionals, health informaticians, and specialists; the frameworks by Barakat et al [50] and the Academy of Medical Royal Colleges [59], which were adapted by Van Houwelingen et al [53] to develop a telehealth framework aimed at nurses; and the telepsychiatry framework by Hilty et al [60], which laid the foundation for telebehavioral health competencies by Maheu et al [39]. 
Figure 3. Development of recent digital health competency frameworks. HITCOMP: Health Information Technology Competencies; TIGER: Technology Informatics Guiding Education Reform.

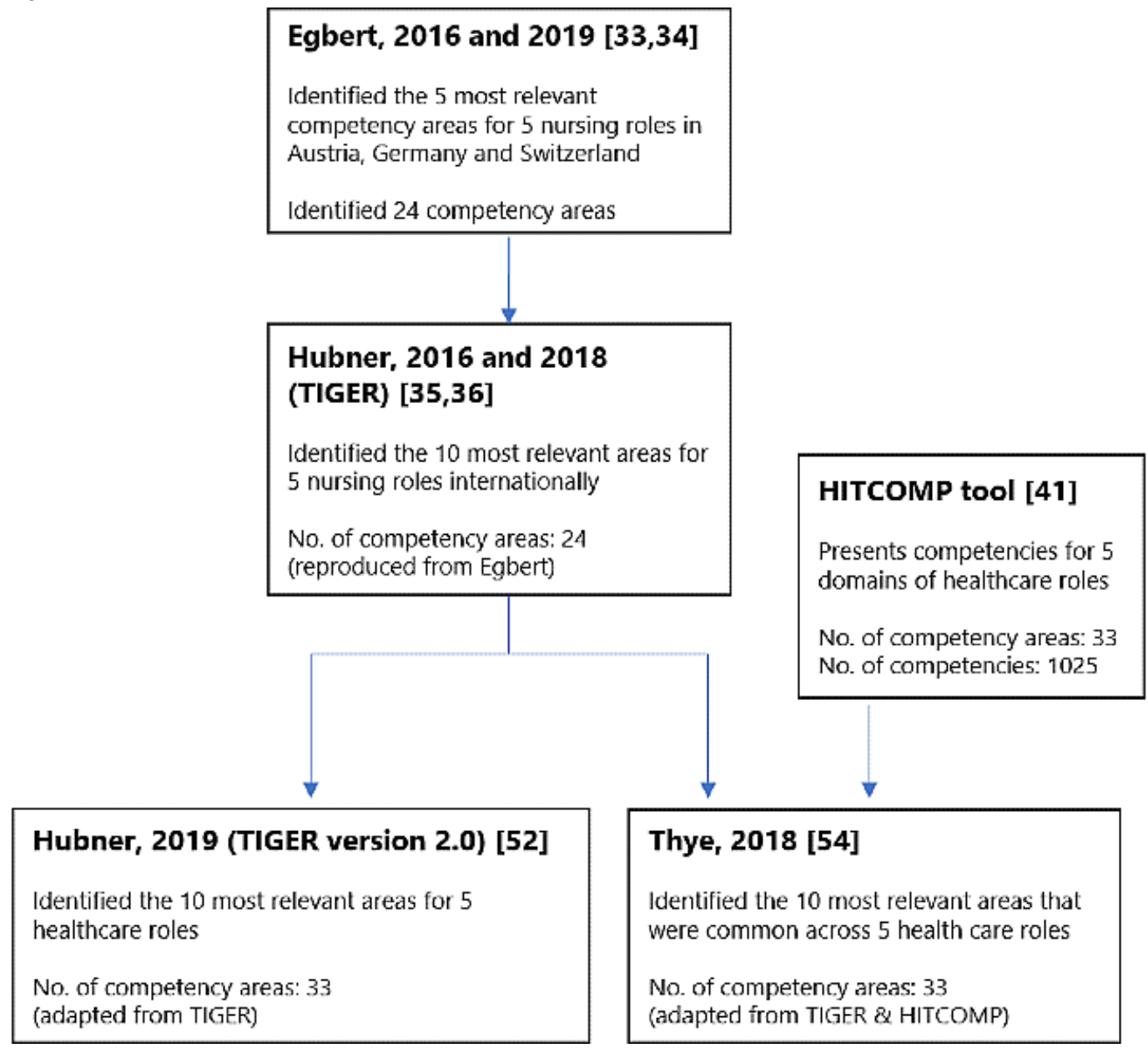

\section{Digital Health Competencies and Categories}

Across the included digital health competency frameworks, the number of competency categories, subcategories, and competencies ranged from 3 to 33,10 to 39 , and 15 to 1025 , respectively. The wide range of reported competencies reflects the scale and specificity of the frameworks. For example, the framework with 15 competencies was focused on telepsychiatry training for psychiatry residents [51], while a framework with 318 competencies was intended for nurses at 4 different levels of practice [21]. Frameworks with multiple categories or subcategories had a larger number of competencies. For example, the eHealth competency framework by the Academy of Medical Royal Colleges presented 20 categories and included 418 competencies [59].

The primary objective of the frameworks was to guide the development of digital health curricula or training initiatives. Thus, 20 frameworks listed specific competencies (eg, knows how to use medical information systems for retrieval of patient data) [48], 6 frameworks cited case studies or provided examples for integration of competencies into curricula or training programs [33-36,45,51,52,58], and 3 frameworks ranked the most relevant competency areas, while the remaining 2 frameworks proposed only broad competency domains. Furthermore, in 12 frameworks, proficiency level in a digital health area or competency was presented according to the hierarchy of a profession or according to the depth of a skill that can be acquired by a health care worker role. For example, Chang et. al [21] presented competencies according to nursing staff seniority level (ie, a beginning nurse, an experienced nurse, an informatics specialist, an informatics innovator). Conversely, AHIEC assigned each competency a level of 1 to 6 (ie, 1: Remembering; 2: Understanding; 3: Applying; 4: Analyzing; 5: Evaluating; 6: Creating), according to the revised Taxonomy of Learning Domain objectives by Bloom, to indicate the depth of a skill that can be acquired by a health care worker role [57].

In addition, the structure of the included digital health competency frameworks varied. Competencies were organized either based on broad informatics categories (ie, computer skills, informatics knowledge, informatics skills) $[21,22,31,32,42,44,45,48,53]$ or a combination of informatics and noninformatics categories (ie, information systems concepts, management concepts, ethical or legal concepts) [38,41,46,59-61] or based on health care worker roles (ie, communicator, collaborator, professional) [33-36,51,52,54,55]. Alternatively, competencies were sorted according to learning outcomes or statements [37,39,40,43,47,49,50,56-58]. For example, the national guideline for Canadian registered nurses sorted competencies according to 3 overarching statements: (1) uses relevant information and knowledge to support the delivery of evidence-informed patient or client care; (2) uses IT in accordance with professional and regulatory standards and 
workplace policies; and (3) uses IT in the delivery of patient or client care [37].

Through thematic analysis, we were able to classify the majority of the competency categories presented in the frameworks into 28 domains. These domains are defined in Textbox 1, details of the analysis are provided in Multimedia Appendix 7 [45], and results of the analysis is presented in Multimedia Appendix 8. Competencies relating to the following domains were found to be prevalent in at least half of the included frameworks: informatics concepts and processes (22/30, 73\%); health information and records management (19/30, 63\%); communication $(19 / 30,63 \%)$; ethics, legal, or regulations $(18 / 30,60 \%)$; privacy and security $(17 / 30,57 \%)$; technical knowledge and support (15/30,50\%); and clinical care delivery $(15 / 30,50 \%)$. Conversely, competencies relating to medicines management (2/30, 7\%) [41,59]; attitudes toward IT (4/30, 13\%) $[48,51,58,60]$; IT advocacy $(5 / 30,17 \%)[21,22,51,55,60]$; and public health $(5 / 30,17 \%)[41,49,52,54,55]$ were found to be uncommon in digital health competency frameworks. Of the 28 identified domains, $20(71 \%)$ were present in at least one-third of the frameworks (Multimedia Appendix 8). 
Textbox 1. Digital health competency domains identified from the included frameworks.

Administration and general management

- Use of administrative information technology (IT) applications to perform tasks and procedures, such as planning and delivery of services, business workflows, and human resource management

Analysis

- Use of IT systems to perform analysis of data, including data visualization, evaluation, and reporting

Attitudes toward IT

- Attitudes and cultural awareness toward the use of IT in patient care

Clinical care delivery

- Utilization of IT for the support of clinical care and practice, including use of assistive technologies and electronic test requesting

Communication

- Use of digital communications (eg, social media, email, etc) to enhance interpersonal skills and to aid in care delivery and decision-making process

Decision support

- $\quad$ Use of IT for clinical practice decision support

Documentation

- Use of IT for appropriate documentation tasks and processes, including knowledge of coding and terminologies

Education and training

- Use of IT in education and training, including e-Learning, mobile learning, and simulation

Ethics, legal, or regulations

- Knowledge of ethical, regulatory, compliance, and legal requirements relating to health IT

Financial management

- Knowledge of financial and account management relating to IT applications, including billing and fiscal aspects

Health information and records management

- Ability to access, collect, store, share, and manage digital health information; use of eHealth records; information and knowledge management

Health care quality and safety

- $\quad$ Ensuring or improving the quality and safety of health care services with the use of IT

Imaging

- Knowledge of biomedical imaging digital technologies

Informatics concepts and processes

- Knowledge and skills in computer basics, information systems, and general health IT use

Integration and interoperability

- Knowledge of integrated health IT applications, health information exchange, and interoperability standards, including coordination and collaboration aspects

IT advocacy

- Play an active role in promoting the use of IT in health care environments

Leadership and executive management

- Providing or enhancing executive leadership skills relating to the use of IT, including setting direction, strategic management, change management, stakeholder management, and governance 
Medicines management

- Management of digital medication records and use of order entry

Patient access and engagement

- $\quad$ Promoting use of IT applications among patients and supporting or empowering patients for self-management, including patient access to patient health records

Privacy and security

- Ensuring that digital data and health information are protected and kept confidential by following privacy and security procedures

Project management

- $\quad$ Knowledge of project management software and associated terminologies

Public health

- Use of IT to inform public health strategies

Remote care

- $\quad$ Provision of care at a distance, including telehealth care, eHealth, mobile health, and related fields

Research

- Appropriate use of IT for research support and innovations

Risk management

- Managing IT-related risks

Systems implementation

- Knowledge and skills about IT systems development, management, and implementation

Technical knowledge and support

- Knowledge of technical aspects of IT systems, including software applications, testing, applied computer science, and IT maintenance and support capabilities

\section{Discussion}

\section{Principal Findings}

Of the 30 digital health competency frameworks, 14 solely targeted nursing staff. The frameworks predominantly originated from high-income countries and were developed based on literature reviews, followed by expert discussions or a Delphi approach. More than half of the included frameworks, especially those providing national-level recommendations, were from gray literature sources. Most frameworks were published between 2016 and 2019, highlighting the growing interest in digital health competencies in recent years.

The purpose of the retrieved digital health competency frameworks and the intended audience was clearly stated in most frameworks. The earliest frameworks and almost half of all the included frameworks were meant for nurses. This could be due to the significantly larger proportion of nurses in the health workforce [65]. Nurses play a crucial role in supporting health care environments by being a constant point of contact between patients and doctors; thus, there are various aspects of digital capabilities that are required of them (eg, using staff scheduling systems, extracting data from clinical systems, navigating decision support systems) [22]. These nursing-focused frameworks have inspired subsequent works for other health care workers. For example, several competency areas subsumed under broad areas for nurses in the TIGER framework [36] were marked as standalone competency areas (ie, communication, legal issues, interoperability and integration, and life cycle management) for a wider spectrum of health care workers in version 2.0 of the TIGER framework [52]. Notably, only one framework was found for allied health professionals (ie, dietitians) [45], which highlights the perceived lack of interest in educating and training this group of workers in digital health. However, the Health Informatics Society of Australia, now known as the Australasian Institute of Digital Health, highlighted the need to focus on allied health care workers as their involvement is becoming increasingly important in decision making to improve patient care and health outcomes [66]. Furthermore, although there were frameworks for doctors and medical students collectively, only one framework was intended solely for undergraduate medical education. The framework was a national guideline for medical students in Canada briefly describing 25 eHealth competencies [55]. Medical practice relies heavily on communication, which is now achieved through various digital means; thus, the skills to utilize a range of digital technologies should be comprehensive and included in medical education [67]. Moreover, with the COVID-19 pandemic, 
doctors are required to handle patient consultations digitally [11]. A 2018 survey conducted by European Medical Students' Association revealed that a majority of medical students rated their eHealth skills to be "poor" or "very poor" and desired for adequate digital health literacy [14].

Most of the included frameworks are useful for application in education or practice, mainly owing to the specificity of competencies, the organization of competencies according to proficiency levels or health care worker roles, and the illustration of case studies and examples to be applicable to various settings. On the other hand, frameworks by Trangenstein et al [43] and Jidkov et al [40] presented only broad competency themes, as it was believed that exhaustive lists of competencies could lead to poor adoption [40]. As the included digital health competency frameworks were heterogeneous in purpose, audience, and setting, it is challenging to determine a single framework as exemplary. Nevertheless, HITCOMP, which was developed via an iterative methodology, was found to be the most comprehensive framework, covering 21 out of the 28 identified competency domains, listing 1025 competencies, and targeting a wide audience of health care workers and medical specialties [41].

The key thrust of work in this area involves competencies related to informatics, followed by eHealth, telehealth or telebehavioral or telepsychiatry, digital capability, and health IT competencies. This distinction may be superficial, given that the definitions and terminologies seem to overlap across frameworks and the nomenclatural differences do not necessarily convey differences in competencies. For example, the interprofessional eHealth framework developed by Thye et al [54] utilized a range of informatics frameworks $[33,41,49]$.

Although frameworks often drew upon each other, there were considerable variations among the identified competencies. The Egbert et al $[33,34]$ framework identified the 5 most relevant competency areas (out of 24) for 5 nursing roles in Austria, Germany, and Switzerland. The TIGER framework [35,36] used the same competency areas and methodology as Egbert et al $[33,34]$ and additionally reached out to experts worldwide for their inputs. The resulting relevant competency areas for a nurse in an IT management role, for example, varied considerably between both frameworks. For this role, competency areas, risk management and project management, ranked the top 5 internationally in the TIGER framework $[35,36]$; however, it was only relevant in 1 out of 3 countries in the Egbert et al [34] framework. In addition, eHealth, telematics, and telehealth, which were ranked as top 5 by Egbert et al [34] for 2 out of 3 countries (ie, Germany and Austria), did not make it to the top 10 list in the TIGER framework $[35,36]$. This suggests that the IT management role for nurses could be defined differently depending on each setting. Hence, a clear definition of the role is important to match the appropriate competency skills to a health care worker role.

In our thematic analysis of the competencies included in the retrieved frameworks, we identified 28 competency domains. The most prevalent domain relates to competencies aimed at providing knowledge on informatics concepts and processes. Examples of these include basic computer knowledge, information systems concepts, and principles of informatics, which are fundamental skills to health care workers intending to maximize the use of digital technologies. The other common domains included the ability of health care workers to manage data from health information systems and records and to be well-versed in digital communications. Most of the health-related data today exist in digital form; therefore, it is imperative for health care workers to be able to understand the purpose, basic structures, use, and storage of electronic health records (EHRs). In addition, as digital health entails new forms of communication (eg, virtual consultations, email, chatbots), it is imperative for health care workers to be able to relate information accurately yet efficiently, timely, and delicately to patients, colleagues, and other collaborating stakeholders [68]. Furthermore, the rise in the adoption and utilization of digital technologies has spurred new issues relating to the use of IT [69], which corresponds to the next two common domains of competencies (ie, ethics, legal, or regulations, and privacy and security). These domains stress the importance of health care workers' adherence to legal and regulatory requirements and to keep up to date with privacy and security policies pertaining to the appropriate use of digital technologies.

Some categories that were found in more recent frameworks, such as attitudes toward the use of IT, medication and prescription, IT advocacy, and public health, reflect the emerging trends in digital capabilities required by health care workers. For example, with the widespread adoption of EHRs and e-prescribing being a key functionality, it is imperative for physicians to be able to perform prescribing tasks efficiently and adapt to new features as systems continually evolve [70]. In addition, as digital technologies have an increasing role in the management of health of communities and populations, frameworks have also started to incorporate competencies related to public health [71]. Similarly, the acceptance of IT and its incorporation into everyday practice hinges on health care workers advocating for their use and being mindful of contextual factors and beliefs that would enable their use in different settings, such as high-income and low- and middle-income countries (LMICs). Other distinct domains such as leadership, administrative, managerial, and financial bring to attention that a digitally competent workforce should also be able to utilize technologies to oversee organizational-level aspects. It was also noted that competencies related to artificial intelligence, robotics, and social media, which are very relevant in current times, were not explicitly mentioned in the included frameworks $[5,9,72]$. One possible explanation could be that some of these are subsumed under broader categories, for example, competencies regarding the use of social media could be part of the communication category, or that these digital areas have yet to be covered in digital health competency frameworks.

From this synthesis of digital health competency frameworks, we would like to propose recommendations for the development of future frameworks (Textbox 2). First, an iterative methodology that includes literature review and consultations with local and international experts is ideal for a comprehensive framework. Second, it is encouraged for upcoming frameworks to explore competency areas that appeared in more recent frameworks, to cover upcoming digital health areas (ie, health 
apps, artificial intelligence, autonomous decision-support systems), and to be open to future revisions to be up to date with technological developments. For example, HITCOMP is projected to continue mapping and aligning competencies with the curriculum and other major initiatives [64]. Finally, the lack of a comprehensive and international framework applicable to allied health professionals and LMICs warrants the development of frameworks that include these populations and settings. For example, only the TIGER framework includes case studies of LMICs, such as China, India, and Nigeria [73].

Textbox 2. Recommendations for the development of digital health competency frameworks.

Methodology:

- Literature review, followed by consultations or Delphi study with local experts, followed by engagement with international experts

Content:

- Explore new competency areas that appeared in recent frameworks (ie, attitudes and advocacy toward the use of information technology (IT), medication management, public health)

- Update competencies based on technological innovations and adoption and emerging evidence (ie, health apps, artificial intelligence, autonomous decision-support systems)

- Include essential interprofessional competencies (ie, informatics concepts and processes, health information management, communication, ethics, legal, or regulations, and privacy and security)

Target audience or setting to include:

- $\quad$ Allied health professionals

- $\quad$ Low- and middle-income countries

Application:

- $\quad$ Provide case studies of integration into curricula or training programs or examples of application in practice

The findings from this review can also inform and guide future training initiatives on digital health. When designing an educational or training program, it may not be possible to cover numerous competencies presented in a framework; rather, the program should focus on a specific set of competencies suitable for a particular group of health care workers, role, level of seniority, geographical, and health care setting. However, the identified competency domains prevalent in more than half of the included frameworks (ie, informatics concepts and processes, health information management, communication, ethics, legal, or regulations, and privacy and security) should be considered essential interprofessional competencies and thus should be incorporated into training and education efforts for any health care worker group. In addition, several digital competencies presented in the included frameworks may already be covered within the existing curriculum. For example, competencies within the Analysis and Research category may have been integrated within epidemiology training and evidence-based medicine education, respectively. Therefore, educators should consider integrating digital health training within existing parts of the curriculum and teaching it in an applied manner as much as possible. For example, the use of EHRs could be incorporated into the internal medicine curriculum.

\section{Strengths and Limitations}

To our knowledge, this is the first consolidation and analysis of existing digital health competency frameworks regardless of the role of health care workers. We performed a thorough search, including several databases and gray literature sources. Our analysis also provides a comprehensive overview of the types of competencies presented in digital health competency frameworks, which will aid in the training and education of health care workers to be digitally competent in relevant areas. Some weaknesses must be kept in mind when interpreting the findings of this review. Although a substantial number of frameworks from gray literature were included, some could have been missed, potentially national guidelines and standards from LMICs. In addition, when performing the thematic analysis, there were frameworks with vague competency categories and overlaps among some categories, leading to differences in opinions during the classification process. However, the 2 reviewers used their expertise to develop and clearly define the domains and allocate categories from frameworks into these domains, first independently and then through a consensus discussion, to reduce bias and classify as appropriately as possible. Although the reviewers aimed to make the classification process as transparent and reproducible as possible, it must be noted that there could be alternate ways of interpreting and classifying and that categorization may differ in the future with the new advances in digital health.

\section{Conclusions}

Of the 30 frameworks included in this scoping review, a majority target nurses, originate from high-income countries, and have been developed using an iterative approach. Our analysis of digital health competency frameworks can help inform the development of future digital health training programs for health care workers. Existing frameworks largely focus on the development of basic IT skills, proficiency in managing health-related information and digital communications, and awareness of ethical, legal, privacy, and security implications relating to IT. Future frameworks and training programs need to take into consideration the evolving nature of digital health and have to be able to incorporate upcoming digital trends, such 
as artificial intelligence and robotics. There is also a need for health professionals.

frameworks focusing on LMICs, medical students, and allied

\section{Acknowledgments}

The authors thank Ms Yasmin Lynda Munro from the Lee Kong Chian School of Medicine, Medical Library, for assistance in formulating the search strategy. They would also like to thank Ms Laura Martinengo, Ms Selina Poon, Ms Christina Tan, Mr Gerard Dunleavy, and Mr Rishi S Nannan Panday for their assistance with screening articles and data extraction. The authors would like to acknowledge the funding support from the Lee Kong Chian School of Medicine, Nanyang Technological University Singapore. JC's and LC's post at Imperial College London is supported by the National Institute for Health Research North West London Applied Research Collaboration.

This research was supported by funding from the World Health Organization Collaborating Centre for Digital Health and Health Education, provided by the Lee Kong Chian School of Medicine and Nanyang Technological University Singapore, Singapore.

\section{Authors' Contributions}

LC conceived the idea for the review and advised on the methodology. NN, DP, BK, and GJ were involved in the literature search, screening, and data extraction. NN and GJ were involved in the thematic analysis. NN analyzed and synthesized the data and drafted the manuscript. JC conceived the idea for the review and supervised the study. All authors reviewed the paper and provided critical inputs.

\section{Conflicts of Interest}

None declared.

\section{Multimedia Appendix 1}

Inclusion and exclusion criteria.

[DOCX File, 50 KB-Multimedia Appendix 1]

\section{Multimedia Appendix 2}

Search strategy for Medical Literature Analysis and Retrieval System Online (MEDLINE).

[DOCX File , 48 KB-Multimedia Appendix 2]

\section{Multimedia Appendix 3}

Keywords used for searching gray literature.

[DOCX File, 52 KB-Multimedia Appendix 3]

\section{Multimedia Appendix 4}

List of organizations whose websites were searched.

[DOCX File , 48 KB-Multimedia Appendix 4]

\section{Multimedia Appendix 5}

Data extraction form.

[DOCX File , 48 KB-Multimedia Appendix 5]

\section{Multimedia Appendix 6}

Details of included studies.

[DOCX File , 68 KB-Multimedia Appendix 6]

\section{Multimedia Appendix 7}

Allocation of competency categories or themes from included frameworks into overarching competency domains.

[DOCX File, 76 KB-Multimedia Appendix 7]

\section{Multimedia Appendix 8}

Competency domains prevalent across 30 digital health competency frameworks. 
[PNG File, 300 KB-Multimedia Appendix 8]

\section{References}

1. Catwell L, Sheikh A. Evaluating eHealth interventions: the need for continuous systemic evaluation. PLoS Med 2009 Aug;6(8):e1000126 [FREE Full text] [doi: 10.1371/journal.pmed.1000126] [Medline: 19688038]

2. Peckham D. Electronic patient records, past, present and future. Paediatr Respir Rev $2016 \operatorname{Aug}(20$ Suppl):8-11. [doi: 10.1016/j.prrv.2016.06.005] [Medline: 27394677]

3. WHO Guideline: Recommendations on Digital Interventions for Health System Strenghtening. World Health Organization. 2019. URL: https://apps.who.int/iris/bitstream/handle/10665/311941/9789241550505-eng.pdf?ua=1 [accessed 2020-10-08]

4. Shaw T, McGregor D, Brunner M, Keep M, Janssen A, Barnet S. What is ehealth (6)? Development of a conceptual model for ehealth: qualitative study with key informants. J Med Internet Res 2017 Oct 24;19(10):e324 [FREE Full text] [doi: 10.2196/jmir.8106] [Medline: 29066429]

5. Global Diffusion of Ehealth: Making Universal Health Coverage Achievable. World Health Organization. 2016. URL: https://apps.who.int/iris/bitstream/handle/10665/252529/9789241511780-eng.pdf?sequence=1 [accessed 2020-10-08]

6. Keasberry J, Scott IA, Sullivan C, Staib A, Ashby R. Going digital: a narrative overview of the clinical and organisational impacts of eHealth technologies in hospital practice. Aust Health Rev 2017 Dec;41(6):646-664. [doi: 10.1071/AH16233] [Medline: 28063462]

7. Nanah A, Bayoumi AB. The pros and cons of digital health communication tools in neurosurgery: a systematic review of literature. Neurosurg Rev 2020 Jun;43(3):835-846. [doi: 10.1007/s10143-018-1043-0] [Medline: 30334173]

8. Mohsin-Shaikh S, Furniss D, Blandford A, McLeod M, Ma T, Beykloo MY, et al. The impact of electronic prescribing systems on healthcare professionals' working practices in the hospital setting: a systematic review and narrative synthesis. BMC Health Serv Res 2019 Oct 22;19(1):742 [FREE Full text] [doi: 10.1186/s12913-019-4554-7] [Medline: 31640689]

9. The Topol Review: Preparing the Healthcare Workforce to Deliver the Digital Future. The NHS Constitution. 2019. URL: https://topol.hee.nhs.uk/ [accessed 2020-10-08]

10. The Government of the Republic of Korea. Flattening the Curve on Covid 19: How Korea Responded to a Pandemic Using ICT. The Government of the Republic of Korea. 2020. URL: http://www.undp.org/content/seoul policy center/en/home/ presscenter/articles/2019/flattening-the-curve-on-covid-19.html [accessed 2020-10-08]

11. Mian A, Khan S. Medical education during pandemics: a UK perspective. BMC Med 2020 Apr 9;18(1):100 [FREE Full text] [doi: 10.1186/s12916-020-01577-y] [Medline: 32268900]

12. Aungst TD, Patel R. Integrating digital health into the curriculum-considerations on the current landscape and future developments. J Med Educ Curric Dev 2020;7:2382120519901275. [doi: 10.1177/2382120519901275] [Medline: 32010795]

13. Stanford Medicine 2020 Health Trends Report: The Rise of the Data-Driven Physician. Stanford Medicine. 2020. URL: http://med.stanford.edu/content/dam/sm/school/documents/Health-Trends-Report/

Stanford\%20Medicine\%20Health\%20Trends\%20Report\%202020.pdf [accessed 2020-10-08]

14. Digital Health in the Medical Curriculum: Addressing the Needs of the Future Health Workforce. European Medical Students' Association Europe. URL: https://emsa-europe.eu/wp-content/uploads/2019/09/

Digital-Health-in-the-Medical-Curriculum_-Addressing-the-Needs-of-the-Future-Health-Workforce.pdf [accessed 2020-10-08]

15. Improving Digital Literacy. Royal College of Nursing. 2017. URL: https://www.rcn.org.uk/professional-development/ publications/pub-006129 [accessed 2020-10-08]

16. Schreiweis B, Pobiruchin M, Strotbaum V, Suleder J, Wiesner M, Bergh B. Barriers and facilitators to the implementation of ehealth services: systematic literature analysis. J Med Internet Res 2019 Nov 22;21(11):e14197 [FREE Full text] [doi: 10.2196/14197] [Medline: 31755869]

17. Adler-Milstein J, Kvedar J, Bates DW. Telehealth among US hospitals: several factors, including state reimbursement and licensure policies, influence adoption. Health Aff (Millwood) 2014 Feb;33(2):207-215. [doi: 10.1377/hlthaff.2013.1054] [Medline: 24493762]

18. Evolution of eHealth in Australia: Achievements, Lessons, and Opportunities. Sydney: National E-Health Transition Authority Ltd. 2016. URL: https://tinyurl.com/yy3xg947

19. Mesko B, Győrffy Z, Kollár J. Digital literacy in the medical curriculum: a course with social media tools and gamification. JMIR Med Educ 2015 Oct 1;1(2):e6 [FREE Full text] [doi: 10.2196/mededu.4411] [Medline: 27731856]

20. Pathipati AS, Azad TD, Jethwani K. Telemedical education: training digital natives in telemedicine. J Med Internet Res 2016 Jul 12;18(7):e193 [FREE Full text] [doi: 10.2196/jmir.5534] [Medline: 27405323]

21. Chang J, Poynton MR, Gassert CA, Staggers N. Nursing informatics competencies required of nurses in Taiwan. Int J Med Inform 2011 May;80(5):332-340. [doi: 10.1016/j.ijmedinf.2011.01.011] [Medline: 21420902]

22. Curran CR. Informatics competencies for nurse practitioners. AACN Clin Issues 2003 Aug;14(3):320-330. [doi: 10.1097/00044067-200308000-00007] [Medline: 12909800]

23. Strudwick G, Nagle L, Kassam I, Pahwa M, Sequeira L. Informatics competencies for nurse leaders: a scoping review. J Nurs Adm 2019 Jun;49(6):323-330. [doi: 10.1097/NNA.00000000000000760] [Medline: 31135640]

24. Gonçalves LS, Wolff L, Staggers N, Peres A. Nursing informatics competencies: an analysis of the latest research. NI 2012 (2012) 2012;2012:127 [ [FREE Full text] [Medline: 24199069] 
25. Peters M, Godfrey C, McInerney P, Baldini SC, Khalil H, Parker D. Scoping Reviews. In: Joanna Briggs Institute Reviewer's Manual. Australia: The Joanna Briggs Institute; 2017.

26. Tricco AC, Lillie E, Zarin W, O'Brien KK, Colquhoun H, Levac D, et al. PRISMA extension for scoping reviews (PRISMA-ScR): checklist and explanation. Ann Intern Med 2018 Oct 2;169(7):467-473. [doi: 10.7326/M18-0850] [Medline: $\underline{30178033}$ ]

27. Pavagadhi D. Digital Health Competency Frameworks for Pre- and In-Service Health Workers from All Health Professions: A Scoping Review Protocol. OSF Registries. URL: https://doi.org/10.17605/OSF.IO/PXFRV

28. Milner RJ, Gusic ME, Thorndyke LE. Perspective: toward a competency framework for faculty. Acad Med 2011 Oct;86(10):1204-1210. [doi: 10.1097/ACM.0b013e31822bd524] [Medline: 21869668]

29. Covidence Systematic Review Software. Veritas Health Innovation. URL: https://www.covidence.org/ [accessed 2020-10-08]

30. Nowell LS, Norris JM, White DE, Moules NJ. Thematic analysis. Int J Quant Method 2017 Oct 2;16(1):160940691773384. [doi: $10.1177 / 1609406917733847]$

31. Staggers N, Gassert CA, Curran C. Informatics competencies for nurses at four levels of practice. J Nurs Educ 2001 Oct;40(7):303-316. [Medline: 11596683]

32. Staggers N, Gassert CA, Curran C. A Delphi study to determine informatics competencies for nurses at four levels of practice. Nurs Res 2002;51(6):383-390. [doi: 10.1097/00006199-200211000-00006] [Medline: 12464758]

33. Egbert N, Thye J, Schulte G, Liebe J, Hackl W, Ammenwerth E, et al. An iterative methodology for developing national recommendations for nursing informatics curricula. Stud Health Technol Inform 2016;228:660-664. [Medline: 27577467]

34. Egbert N, Thye J, Hackl WO, Müller-Staub M, Ammenwerth E, Hübner U. Competencies for nursing in a digital world. Methodology, results, and use of the DACH-recommendations for nursing informatics core competency areas in Austria, Germany, and Switzerland. Inform Health Soc Care 2019;44(4):351-375. [doi: 10.1080/17538157.2018.1497635] [Medline: 30148411]

35. Hübner U, Shaw T, Thye J, Egbert N, Marin H, Ball M. Towards an international framework for recommendations of core competencies in nursing and inter-professional informatics: the tiger competency synthesis project. Stud Health Technol Inform 2016;228:655-659. [Medline: 27577466]

36. Hübner U, Shaw T, Thye J, Egbert N, Marin HD, Chang P, et al. Technology informatics guiding education reform - tiger. Methods Inf Med 2018 Jun;57(S 01):e30-e42 [FREE Full text] [doi: 10.3414/ME17-01-0155] [Medline: 29956297]

37. Nagle LM, Crosby K, Frisch N, Borycki E, Donelle L, Hannah K, et al. Developing entry-to-practice nursing informatics competencies for registered nurses. Stud Health Technol Inform 2014;201:356-363. [Medline: 24943567]

38. Applied Public Health Informatics Competency Model. Public Health Informatics Institute. 2016. URL: https://www. phii.org/resources/view/9462/applied-public-health-informatics-competency-model [accessed 2020-10-08]

39. Maheu MM, Drude KP, Hertlein KM, Lipschutz R, Wall K, Hilty DM. Correction to: an interprofessional framework for telebehavioral health competencies. J Technol Behav Sci 2018 Mar 5;3(2):108-140. [doi: 10.1007/s41347-018-0046-6]

40. Jidkov L, Alexander M, Bark P, Williams JG, Kay J, Taylor P, et al. Health informatics competencies in postgraduate medical education and training in the UK: a mixed methods study. BMJ Open 2019 Mar 30;9(3):e025460. [doi: 10.1136/bmjopen-2018-025460] [Medline: 30928942]

41. Health Information Technology Competencies. 2020. URL: http://hitcomp.org/competencies/ [accessed 2020-10-08]

42. National Informatics Standards for Nurses and Widwives. Australia: Australian Nursing and Midwifery Federation, Federal Office. 2015. URL: http://anmf.org.au/documents/National Informatics Standards For Nurses And Midwives.pdf [accessed 2020-10-08]

43. Trangenstein PA, Weiner EE, Gordon JS, McArthur D. Nursing informatics for future nurse scholars: lessons learned with the doctorate of nursing practice (DNP). Stud Health Technol Inform 2009;146:551-555. [Medline: 19592903]

44. Westra BL, Delaney CW, Delaney C. Informatics competencies for nursing and healthcare leaders. AMIA Annu Symp Proc 2008 Nov 6:804-808 [FREE Full text] [Medline: 18998803]

45. Ayres EJ, Greer-Carney JL, Fatzinger McShane PE, Miller A, Turner P. Nutrition informatics competencies across all levels of practice: a national Delphi study. J Acad Nutr Diet 2012 Dec;112(12):2042-2053 [FREE Full text] [doi: 10.1016/j.jand.2012.09.025] [Medline: 23174690]

46. Collins S, Yen P, Phillips A, Kennedy MK. Nursing informatics competency assessment for the nurse leader: the delphi study. J Nurs Adm 2017 Apr;47(4):212-218. [doi: 10.1097/NNA.0000000000000467] [Medline: 28333789]

47. Brunner M, McGregor D, Keep M, Janssen A, Spallek H, Quinn D, et al. An ehealth capabilities framework for graduates and health professionals: mixed-methods study. J Med Internet Res 2018 May 15;20(5):e10229 [FREE Full text] [doi: 10.2196/10229] [Medline: 29764794]

48. Hwang HG, Chen RF, Chang LH, Hsiao JL. A study of the informatics literacy of clinical nurses in Taiwan. Comput Inform Nurs 2008;26(5):290-299. [doi: 10.1097/01.NCN.0000304836.70133.d1] [Medline: 18769184]

49. Mantas J, Ammenwerth E, Demiris G, Hasman A, Haux R, Hersh W, IMIA Recommendations on Education Task Force. Recommendations of the international medical informatics association (IMIA) on education in biomedical and health informatics. First revision. Methods Inf Med 2010 Jan 7;49(2):105-120. [doi: 10.3414/ME5119] [Medline: 20054502] 
50. Barakat A, Woolrych RD, Sixsmith A, Kearns WD, Kort HS. Ehealth technology competencies for health professionals working in home care to support older adults to age in place: outcomes of a two-day collaborative workshop. Med 20 2013;2(2):e10 [FREE Full text] [doi: 10.2196/med20.2711] [Medline: 25075233]

51. Crawford A, Sunderji N, López J, Soklaridis S. Defining competencies for the practice of telepsychiatry through an assessment of resident learning needs. BMC Med Educ 2016 Jan 26;16:28 [FREE Full text] [doi: 10.1186/s12909-016-0529-0] [Medline: 26813286]

52. Hübner U, Thye J, Shaw T, Elias B, Egbert N, Saranto K, et al. Towards the tiger international framework for recommendations of core competencies in health informatics 2.0: extending the scope and the roles. Stud Health Technol Inform 2019 Aug 21;264:1218-1222. [doi: 10.3233/SHTI190420] [Medline: $\underline{31438119}$ ]

53. van Houwelingen CT, Moerman AH, Ettema RG, Kort HS, Ten Cate O. Competencies required for nursing telehealth activities: a Delphi-study. Nurse Educ Today 2016 Apr;39:50-62 [FREE Full text] [doi: 10.1016/j.nedt.2015.12.025] [Medline: 27006033]

54. Thye J, Shaw T, Hüsers J, Esdar M, Ball M, Babitsch B, et al. What are inter-professional ehealth competencies? Stud Health Technol Inform 2018;253:201-205. [Medline: 30147073]

55. eHealth Competencies for Undergraduate Medical Education. Canada: The Association of Faculties of Medicine of Canada. 2014. URL: https://www.infoway-inforoute.ca/en/component/edocman/

3400-ehealth-competencies-for-undergraduate-medical-education/view-document?Itemid=101 [accessed 2020-10-08]

56. A HealthCare Digital Capabilities Framework. England: NHS. 2018. URL: https://www.hee.nhs.uk/sites/default/files/ documents/Digital\%20Literacy\%20Capability\%20Framework\%202018.pdf [accessed 2020-10-08]

57. Health Informaticscope, Careers and Competencies. Australia: Australian Health Informatics Education Council. 2011. URL: https://www.ahiec.org.au/docs/AHIEC HI Scope Careers and Competencies V1-9.pdf [accessed 2020-10-08]

58. Honey M, Collins E, Britnell S. Guidelines: Informatics for Nurses Entering Practice. University of Auckland. 2018. URL: https://cdn.ymaws.com/www.hinz.org.nz/resource/resmgr/resources/Guidelines Informatics for n.pdf [accessed 2020-10-08]

59. E Health Competency Framework - Defining the Role of the Expert Clinician. Scotland: Academy of Medical Royal Colleges. 2011. URL: https://www.physio-pedia.com/images/f/f0/EHealth_Competancy_Framework.pdf [accessed 2020-10-08]

60. Hilty DM, Crawford A, Teshima J, Chan S, Sunderji N, Yellowlees PM, et al. A framework for telepsychiatric training and e-health: competency-based education, evaluation and implications. Int Rev Psychiatry 2015;27(6):569-592. [doi: 10.3109/09540261.2015.1091292] [Medline: 26540642]

61. Recommendations on a Common Framework for Mapping Health Professionals' eHealth Competencies. Joint Action to Support the eHealth Network. 2018. URL: https://jasehn.eu/wordpress/wp-content/uploads/2018/07/JAseHN_D7.1. 3 RECOMMENDATIONS common Framework mapping health profession....pdf [accessed 2020-10-08]

62. Digital Literacy. Health Education England. URL: https://www.hee.nhs.uk/our-work/digital-literacy [accessed 2020-10-08]

63. Joint Action to support the eHealth Network JAseHN 677102 - Joint Actions. European Commission. URL: https://webgate. ec.europa.eu/chafea pdb/health/projects/677102/workpackages [accessed 2020-09-10]

64. EU US eHealth Works to Improve Global Workforce Development. Technology Informatics Guiding Education Reform. 2017. URL: https://tutcris.tut.fi/portal/files/12978862/Eu_us_ehealth_workforce_development.pdf [accessed 2020-10-08]

65. Nursing and Midwifery. World Health Organization. URL: https://www.who.int/news-room/fact-sheets/detail/ nursing-and-midwifery [accessed 2020-10-08]

66. Allied Health Professionals: the Untapped Potential in Digital Health. Health Informatics Society of Australia. 2019. URL: https://www.hisa.org.au/wp-content/uploads/2019/02/Allied-Health-Informatics-Position-Statement draft.pdf [accessed 2020-10-08]

67. Wells KM. Social media in medical school education. Surgery 2011 Jul;150(1):2-4. [doi: 10.1016/j.surg.2011.05.023] [Medline: 21683853]

68. Griffiths F, Armoiry X, Atherton H, Bryce C, Buckle A, Cave J, et al. The role of digital communication in patient-clinician communication for NHS providers of specialist clinical services for young people [the Long-term conditions Young people Networked Communication (LYNC) study]: a mixed-methods study. Southampton (UK): NIHR Journals Library 2018. [Medline: 29485818]

69. Vayena E, Haeusermann T, Adjekum A, Blasimme A. Digital health: meeting the ethical and policy challenges. Swiss Med Wkly 2018;148:w14571 [FREE Full text] [doi: 10.4414/smw.2018.14571] [Medline: 29376547]

70. Abramson EL, Patel V, Pfoh ER, Kaushal R. How physician perspectives on e-prescribing evolve over time. A case study following the transition between EHRS in an outpatient clinic. Appl Clin Inform 2016 Oct 26;7(4):994-1006 [FREE Full text] [doi: 10.4338/ACI-2016-04-RA-0069] [Medline: 27786335]

71. Gamache R, Kharrazi H, Weiner JP. Public and population health informatics: the bridging of big data to benefit communities. Yearb Med Inform 2018 Aug;27(1):199-206 [FREE Full text] [doi: 10.1055/s-0038-1667081] [Medline: 30157524]

72. Alraies MC, Raza S, Ryan J. Twitter as a new core competency for cardiologists. Circulation 2018 Sep 25;138(13):1287-1289. [doi: 10.1161/CIRCULATIONAHA.118.032999] [Medline: 30354418]

73. EU US eHealth Work Project H2020-SC1-HCO13-2016. Healthcare Information and Management Systems Society. 2016. URL: https://www.himss.org/euus-ehealth-work-projects-global-case-studies [accessed 2020-10-08] 


\author{
Abbreviations \\ AHIEC: Australian Health Informatics Council \\ CINAHL: Cumulative Index to Nursing and Allied Health Literature \\ EHR: electronic health record \\ EMBASE: Excerpta Medica dataBASE \\ ERIC: Education Resources Information Centre \\ HITCOMP: Health Information Technology Competencies \\ IMIA: International Medical Informatics Association \\ IT: information technology \\ LMIC: low- and middle-income country \\ MEDLINE: Medical Literature Analysis and Retrieval System Online \\ NHS: National Health Services \\ TIGER: Technology Informatics Guiding Education Reform
}

Edited by G Eysenbach; submitted 22.07.20; peer-reviewed by S Li, K Day; comments to author 01.09.20; revised version received 15.09.20; accepted 15.09.20; published 05.11.20

Please cite as:

Nazeha N, Pavagadhi D, Kyaw BM, Car J, Jimenez G, Tudor Car L

A Digitally Competent Health Workforce: Scoping Review of Educational Frameworks

J Med Internet Res 2020;22(11):e22706

URL: https://www.jmir.org/2020/11/e22706

doi: $10.2196 / 22706$

PMID: 33151152

(CNuraini Nazeha, Deepali Pavagadhi, Bhone Myint Kyaw, Josip Car, Geronimo Jimenez, Lorainne Tudor Car. Originally published in the Journal of Medical Internet Research (http://www.jmir.org), 05.11.2020. This is an open-access article distributed under the terms of the Creative Commons Attribution License (https://creativecommons.org/licenses/by/4.0/), which permits unrestricted use, distribution, and reproduction in any medium, provided the original work, first published in the Journal of Medical Internet Research, is properly cited. The complete bibliographic information, a link to the original publication on http://www.jmir.org/, as well as this copyright and license information must be included. 